ADLFI. Archéologie de la France -

\title{
Arrondissement de Carpentras
}

\section{Claude Ayme}

URL : http://journals.openedition.org/adlfi/6109

ISSN : 2114-0502

Éditeur

Ministère de la culture

Référence électronique

Claude Ayme, "Arrondissement de Carpentras », ADLFI. Archéologie de la France - Informations [En ligne], Provence-Alpes-Côte d'Azur, mis en ligne le 01 mars 2007, consulté le 03 mai 2019. URL : http:// journals.openedition.org/adlfi/6109

Ce document a été généré automatiquement le 3 mai 2019.

(c) Ministère de la Culture et de la Communication, CNRS 


\title{
Arrondissement de Carpentras
}

\author{
Claude Ayme
}

Identifiant de l'opération archéologique : 8475

Date de l'opération : 2007 (PR)

Inventeur(s) : Ayme Claude (ASS)

1 En 2007, les bonnes conditions climatiques de début d'année nous ont permis de reprendre la prospection sur plusieurs anciennes stations (BSR PACA, 2006:236-237). Nous avons ainsi prospecté la deuxième station en termes d'importance de notre zone (Fontainiers st. 2) et réexaminé l'ensemble du mobilier que nous y avions découvert auparavant.

\section{La station des Fontainiers 2 (Carpentras / Mazan)}

2 Située de part et d'autre de la départementale RD 974 sur les communes de Carpentras et de Mazan, à une altitude de $135 \mathrm{~m}$, cette station est au coeur de la basse terrasse (Würm de la chronologie alpine) du bassin de Carpentras/Mormoiron.

3 Positionnée sur un replat dominant au sud le ruisseau de l'Eyguette et au nord le ruisseau de la Combe d'une dizaine de mètres, cette station a livré, sur une dizaine de parcelles, 641 artefacts de facture paléolithique dont 231 pièces, 103 nucléus et 307 éclats. Trois concentrations principales sont apparues dont une particulièrement dense sur un rectangle de $130 \mathrm{~m}$ x $30 \mathrm{~m}$.

4 L'indice Levallois de 27,1\% est comparable à l'indice le plus bas que nous ayons jusqu'à présent identifié (Station du Bois à Caromb) parmi les stations des basses terrasses du bassin de Carpentras / Mormoiron (entre 26,6 et 35,4\%). L'industrie récoltée est de débitage Levallois non trié. L'indice de facettage de 30,5\% est assez élevé : les talons facettés sont surtout présents sur les supports Levallois. L'indice laminaire est, comme à la station du Bois 1 , assez faible (6,9\%). 
Comme sur de nombreuses autres stations du bassin de Carpentras, les nucléus sont nombreux ( $16,1 \%$ du total des grands éclats), traduisant ainsi une conservation différentielle importante.

6 Sur les 97 nucléus entiers, les nucléus Levallois sont dominants (42,3\%), suivis par les nucléus globuleux présentant de nombreux enlèvements (113\%), les nucléus à une seule surface d'exploitation (10,3\%), les nucléus informes (7,2\%), les nucléus à deux surfaces d'exploitation $(6,2 \%)$. Les nucléus prismatiques rares $(2,9 \%)$ et de mauvaise facture (négatifs d'enlèvement courts) sont en concordance avec l'indice laminaire bas. À signaler également la présence d'une dizaine de blocs testés (percuteurs ?) présentant un ou deux enlèvements de peu d'étendue.

7 Parmi les 41 nucléus Levallois, nous dénombrons 10 nucléus à éclats Levallois préférentiel (7 à éclat préférentiel quadrangulaire, 3 à pointe Levallois), 30 à méthode récurrente (6 à méthode unipolaire, 11 à méthode bipolaire, 13 à méthode centripète) et 1 mixte à éclat préférentiel sur une face et à méthode récurrente unipolaire sur l'autre. Trois de ces nucléus Levallois ont été réalisés sur la face inférieure d'éclat. Cinq autres nucléus réalisés sur la face inférieure d'éclats et ne présentant qu'un ou deux enlèvements ont été considérés comme des nucléus Kombewa (un seul éclat Kombewa a été découvert).

8 La présence de ces nombreux nucléus, de nombreux éclats corticaux à cortex résiduel et de couteaux à dos naturel témoigne d'une activité de débitage sur le site comme sur la quasi-totalité des stations du bassin de Carpentras.

Parmi les éléments différenciant cette station, plusieurs points apparaissent :

- Deux nucléus Levallois ont été repris en outils : racloir.

- De nombreux nucléus (Levallois et Kombewa) ont été réalisés sur éclat épais.

- Dans le même cadre d'utilisation de face inférieure d'éclats, dix pièces présentent un amincissement. Cinq amincissements latéraux correspondent à un racloir sur face plane, à un racloir à dos aminci, à deux encoches et à un perçoir. Cinq bases amincies correspondent à une pièce multiple (racloir à retouche biface et grattoir), à deux encoches sur la face supérieure, à l'enlèvement d'un bulbe proéminent sur une lame Levallois et à la mise en place sur un éclat Levallois épais d'un "pédoncule» ayant probablement facilité la préhension de cette pièce [ (Fig. $\mathrm{n}^{\circ} 1$ : Station des Fontainiers 2 , mobilier lithique), 1 ].

10 Parmi les pièces, nous dénombrons de nombreux éclats Levallois, quelques rares lames Levallois [ (Fig. $\mathrm{n}^{\circ} 1$ : Station des Fontainiers 2, mobilier lithique), 3 et 4] et cinq pointes Levallois. Le fort concassage rendant très difficile la lecture des retouches et la détermination des outils, nous avons tout de même pu identifier dix-huit racloirs réalisés pour les deux tiers d'entre eux sur support non Levallois. Parmi les cinq racloirs réalisés sur support Levallois, trois, peu concassés, ont pu être déterminés [ (Fig. $\mathrm{n}^{\circ} 1$ : Station des Fontainiers 2, mobilier lithique), 3].

11 Le réexamen de cette série nous a permis de mettre en évidence une utilisation de la technique d'amincissement par retouches inverses sur éclat plus fréquente sur cette station que sur les séries préalablement étudiées. La poursuite de cette analyse dans les mois qui viennent devrait nous permettre de confronter les particularités de celle-ci avec d'autres stations non encore étudiées sur notre zone.

AYME Claude 


\section{ANNEXES}

Fig. $\mathrm{n}^{\circ} 1$ : Station des Fontainiers 2 , mobilier lithique

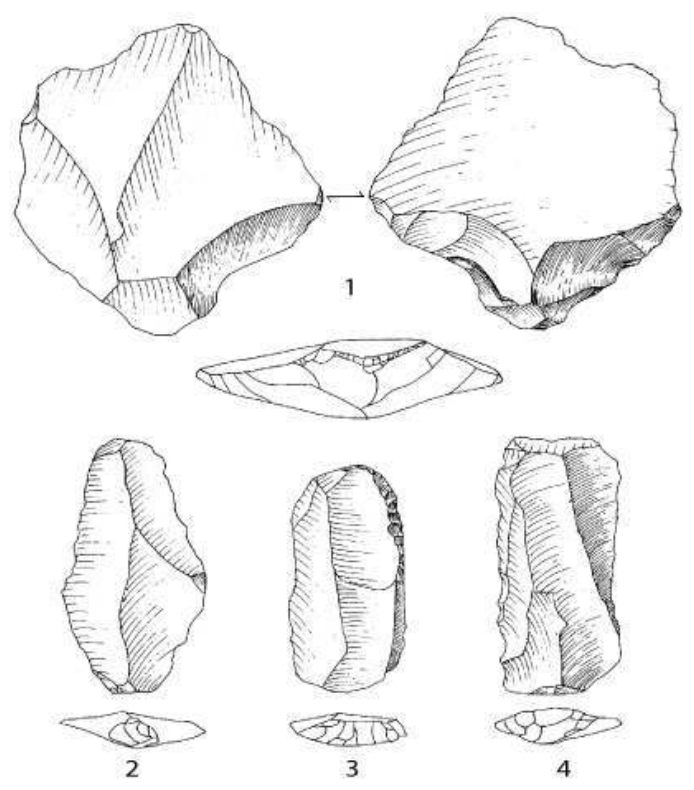

1. éclat Levallois épais présentant un " pédonculé » :

2. pointe Levallois ;

3. racloir simple convexe sur lame Levallois;

4. lame Levallois.

Auteur(s) : Ayme, Claude. Crédits : ADLFI (2007)

INDEX

Index chronologique : Paléolithique

Index géographique : Provence-Alpes-Côte d'Azur, Vaucluse (84), Carpentras, Mazan

operation Prospection (PR)

AUTEURS

CLAUDE AYME 